\author{
Massimo Antonelli \\ Giorgio Conti \\ Giuseppe Bello
}

\section{New niches for NIV: ahead with caution!}

Received: 23 April 2013

Accepted: 25 April 2013

Published online: 14 May 2013

(C) Springer-Verlag Berlin Heidelberg and ESICM 2013

M. Antonelli · G. Conti · G. Bello

Department of Anesthesiology and Intensive Care,

Agostino Gemelli University Hospital,

Università Cattolica del Sacro Cuore, Rome, Italy

\section{Antonelli (}

Department of Anesthesiology and Intensive Care, Policlinico Universitario A. Gemelli, Università Cattolica del Sacro Cuore, Largo A. Gemelli 8, 00168 Rome, Italy

e-mail: m.antonelli@rm.unicatt.it

Non-invasive ventilation (NIV) has assumed a central role in the treatment of patients with both hypoxemic and hypercapnic acute respiratory failure (ARF) [1]. The most convincing evidence supporting NIV as a first-line treatment for ARF has been reported in selected patients with either severe exacerbation of chronic obstructive pulmonary disease or acute cardiogenic pulmonary edema (CPE) [1]. The main reason for using NIV in these patients is to obviate the need for endotracheal intubation (ETI) and to accelerate the discontinuation of mechanical ventilation, thereby improving patient comfort and preserving airway defense mechanisms.

Recent advances in the understanding of the physiological aspects of using NIV through different interfaces and ventilator settings have led to improved patientmachine interaction, enhancing a favorable NIV outcome. In this context, great efforts have been expended in attempts to overcome the problems generated by gas leakage and dead space during NIV. As a consequence, mechanical ventilators have also been implemented with modalities dedicated to delivering NIV [2].

Over the last two decades, investigations on alternative applications of NIV in the acute care setting have reported encouraging results for the treatment of ARF. This and the previous issue of Intensive Care Medicine contain two papers on the use of NIV to treat respiratory failure in two different and - to date-poorly investigated scenarios. Chiumello et al. [3] report the results of a meta-analysis on the use of NIV in chest trauma patients, while in a letter, Rucci et al. [4] described the use of NIV during urgent coronary angiography in a patient with ARF secondary to CPE.

The first application of non-invasive positive airway pressure in the treatment of a patient with chest injuries was reported by Lyman A. Brewer III in 1944, in Cassino, Italy, during World War II, using a portable anaesthetic machine and a face mask [5]. Subsequently, starting in the early 1980s, several studies on the treatment of trauma patients were conducted. In 2002, the British Thoracic Society guidelines on the use of NIV in chest wall trauma patients with respiratory failure included the recommendation for NIV, although supported by low evidence, in those patients who remain hypoxic despite adequate regional anaesthesia and high flow oxygen [6]. Conversely, in the Canadian Medical Association guidelines published in 2011, Keenan et al. [1] made no recommendation on the use of NIV in chest trauma and respiratory distress patients because of insufficient evidence.

That said, what does the new study by Chiumello et al. [3] add to our current knowledge? These authors performed a systematic review and meta-analysis of all randomized controlled trials and observational studies on NIV in chest trauma. They screened ten studies that enrolled a total number of 368 adults with chest trauma who developed mild to severe ARF and were treated with face mask NIV. These studies enrolled patients admitted to the intensive care unit (ICU) or emergency department. Non-invasive positive pressure was delivered as continuous positive airway pressure, bi-level positive airway pressure and as non-invasive pressure support ventilation. Five trials (219 patients) reported information on mortality without heterogeneity across studies. There were $3 / 101(3 \%)$ deaths in the NIV group compared to 27/118 (22.9\%) in the control group, 
with a summary relative risk for patients treated with NIV compared with standard care (oxygen therapy and invasive mechanical ventilation) of 0.26 (95\% confidence interval $0.09-0.71, p=0.003)$. NIV was found to significantly reduce the intubation rate and overall complications and infection and to increase arterial oxygenation, without affecting the arterial partial pressure of carbon dioxide $\left(\mathrm{PaCO}_{2}\right)$. Based on these results, the authors suggest that NIV could be useful in the management of ARF due to chest trauma. Such a conclusion requires further discussion.

Importantly, in this meta-analysis, binary outcomes, including complications, infections, intubation rate, and mortality, were highly homogeneous across studies. However, there was heterogeneity across the studies for the length of ICU stay, and the heterogeneity was more significant for a number of continuous variables, such as oxygenation, $\mathrm{PaCO}_{2}$, respiratory rate, and length of hospital stay. Furthermore, as the authors correctly acknowledge in their article, the number of eligible studies was relatively small. When evaluating the results of any meta-analysis, we should bear in mind that any interpretation of the data may be flawed by potential confounding factors among the different study populations. This is particularly true when there are poor homogeneity levels with a limited number of studies.

Given the data presented by Chiumello et al., the use of NIV in patients with ARF due to chest injuries seems to be advisable. However, as the actual evidence of the benefit of NIV in chest trauma patients has still not been convincingly elucidated in full, the use of NIV in this setting cannot be widely recommended. The researcher should be aware that a trial of NIV is not without risk, and extreme caution must be exercised when using NIV in severe chest trauma patients. The success of NIV in patients with ARF depends on several factors, including the availability of a highly trained professional staff, careful patient selection, and close monitoring. In this specific setting, identifying patients who are proper candidates for NIV and those in whom NIV is not likely to be effective can help to avoid NIV application or unnecessary, dangerous delays before
ETI $[7,8]$. Moreover, knowing the factors affecting the likelihood of success of NIV may be useful in deciding the duration of a ventilation trial. More specifically, in patients with chest trauma, practicing clinicians should accurately define the severity of injuries and respiratory distress before starting NIV. In the absence of solid supportive data, NIV should be started with prudence and under strict control in chest trauma patients with severe respiratory conditions.

In other clinical settings, the use of NIV may be open to question. In the report of Rucci et al. [4], an 86-year-old woman who presented to the emergency department with ARF $\left[\mathrm{PaO}_{2} /\right.$ fraction of inspired oxygen $\left(\mathrm{FiO}_{2}\right)<200$ ] and CPE due to acute myocardial infarction was successfully treated with NIV. Her echocardiogram revealed akinesia of the lower wall and an ejection fraction of $30 \%$. Urgent coronary revascularization lasted $60 \mathrm{~min}$, and NIV was kept throughout the procedure, avoiding ETI. In this context, the Canadian Medical Association suggests, with a high grade of recommendation, the use of NIV in patients who have CPE and ARF, provided it is applied in the absence of shock or acute coronary syndrome requiring urgent coronary revascularization [1]. Moreover, data from the American Society of Anesthesiologists Closed Claims database suggest that anesthesia at remote locations is associated with a significant risk of adverse effects [9]. Additionally, these data show that cardiology catheterization and electrophysiology laboratories are among facilities that are most commonly involved in remote location claims, second only to the gastrointestinal suite.

In our opinion, again, in populations of patients in whom NIV success has not been clearly demonstrated, NIV must be applied in suitable hospital facilities and managed by healthcare providers with a high level of competence in the field. When considering NIV in these patients, we advise strict adherence to accepted criteria for patient selection and discourage any audacious (but potentially risky!) applications.

Chiumello et al. [3] and Rucci [4] et al. deal with two interesting issues that can be the basis for future research.

Conflicts of interest None.

\section{References}

1. Keenan SP, Sinuff T, Burns KE, Muscedere J, Kutsogiannis J, Mehta S, Cook DJ, Ayas N, Adhikari NK, Hand L, Scales DC, Pagnotta R, Lazosky L, Rocker G, Dial S, Laupland K, Sanders K, Dodek P, Canadian Critical Care Trials Group/Canadian Critical Care Society Noninvasive Ventilation Guidelines Group (2011) Clinical practice guidelines for the use of noninvasive positive-pressure ventilation and noninvasive continuous positive airway pressure in the acute care setting. CMAJ 183:E195-E214
2. Vignaux L, Tassaux D, Carteaux G, Roeseler J, Piquilloud L, Brochard L, Jolliet P (2010) Performance of noninvasive ventilation algorithms on ICU ventilators during pressure support: a clinical study. Intensive Care Med 36:2053-2059

3. Chiumello D, Coppola S, Froio S, Gregoretti C, Consonni D (2013) Noninvasive ventilation in chest trauma: systematic review and meta-analysis. Intensive Care Med. doi: 10.1007/s00134-013-2901-4
4. Rucci G, Casale T, Nava S (2013) First use of non-invasive ventilation during urgent coronary stenting in acute myocardial infarction complicated by pulmonary edema. Intensive Care Med. doi:10.1007/s00134-013-2916-X

5. Brewer LA 3rd (1969) Wounds of the chest in war and peace, 1943-1968. Ann Thorac Surg 7:387-408

6. BTS Standards of Care Committee (2002) Non-invasive ventilation in acute respiratory failure. Thorax 57:192-211 
7. Antonelli M, Conti G, Moro ML, Esquinas A, Gonzalez-Diaz G, Confalonieri M, Pelaia P, Principi T, Gregoretti C, Beltrame F, Pennisi MA, Arcangeli A, Proietti R, Passariello M, Meduri GU (2001) Predictors of failure of noninvasive positive pressure ventilation in patients with acute hypoxemic respiratory failure: a multicenter study. Intensive Care Med 27:1718-1728
8. Antonelli M, Conti G, Esquinas A, Montini L, Maggiore SM, Bello G, Rocco M, Maviglia R, Pennisi MA, Gonzalez-Diaz G, Meduri GU (2007) A multiple-center survey on the use in clinical practice of noninvasive ventilation as a first-line intervention for acute respiratory distress syndrome. Crit Care Med 35:18-25
9. Metzner J, Posner KL, Domino KB (2009) The risk and safety of anesthesia at remote locations: the US closed claims analysis. Curr Opin Anaesthesiol 22:502-508 